\title{
Cytological studies on two species of Epipogium, myco-heterotrophic orchids
}

\author{
Mikio Aoyama \\ Botanical Garden, Technical Center, Hiroshima University, \\ 1-3-1, Kagamiyama, Higashi-Hiroshima City 739-8526, Japan \\ Author for correspondence: (maoyama@hiroshima-u.ac.jp) \\ Received January 14, 2011; accepted February 25, 2011
}

\begin{abstract}
Cytological studies in two species of Epipogium, myco-heterotrophic orchids, were carried out. Epipogium roseum had the chromosome number of $2 n=c a .70,2 n=35_{\text {II }}$ and $n=35$, that was different from the previous count of $2 n=68$ (Singh 1983 ). The chromosome complement at resting stage showed the complex chromocenter type, and the metaphase II chromosomes in meiosis showed a gradual decrease in chromosome length from 1.7-0.7 $\mu \mathrm{m}$. Epipogium aphyllum had the chromosome number of $2 \mathrm{n}=72$, $2 n=36_{\text {II }}$ and $n=36$, that was different from the previous counts of $n=34$ (Francini 1930, Afzelius 1954) and 2n=68 (Gurzenkov 1973, Uhrikova and Majovsky 1980). The chromosome complement at resting stage showed the complex chromocenter type and the metaphase II chromosomes in meiosis showed a bimodal karyotype in length consisted of three large chromosomes varied from

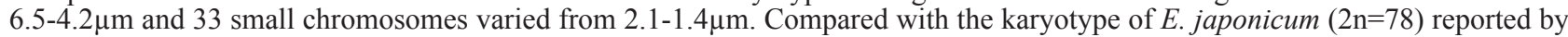
the author (2008), three species of Epipogium were different in chromosome number and length and karyotypes at resting stage and metaphase chromosomes from each other. Though, if it was thought that the one large chromosome of E. aphyllum was derived from the fusion of two small chromosomes of E. japonicum, the chromosome complements of both species were more closely allied than that of E. roseum.
\end{abstract}

KEYWORDS: Chromosome numbers, Epipogium aphyllum, Epipogium roseum, Myco-heterotrophic orchid

Cytological studies of orchids have been done mainly in ornamental epiphytic species for a long time, however, those of myco-heterotrophic orchids have been scarcely described since their good, growing meristematic tissues have not been easily collected due to very small and rare habitats with a few individual plants, very short, aboveground growing season, and very difficult for cultivation. Thus, only 13 species among the 37 myco-heterotrophic orchids of Japan have been cytologically studied up to the present.

Nineteen species of Epipogium have been described in the myco-heterotrophic Epipogium. However, most of them have been recognized as synonyms, and only three species of E. aphyllum, E. roseum and E. japonicum have been accepted as the distinct species (Govaerts et al. 2006). In this paper, karyotype analysis in two mycoheterotrophic E. aphyllum and E. roseum were dealt with, and their karyotypes were compared with those of E. japonicum previously reported (Aoyama 2008).

\section{Materials and Methods}

Epipogium roseum (D. Don) Lindl. (Japanese name: Tashiro-ran) is distributed widely in tropical to subtropical regions in Asia including Southeastern Japan down to Australia and way far to Africa. This species grows rarely in Castanopsis forests of the warm temperate zone. Three plants of the species used in this study were collected in the altitude approximately $15 \mathrm{~m}$ above the sea level in Hiroshima City, Japan in early July, 2009 (Fig. 1).

Epipogium aphyllum Sw. (Japanese name: Torakichiran) is distributed widely in Northern Eurasia Continent including Northern Japan. This species occurs rarely in coniferous forests of the subalpine zone. Two plants of the species used in the present observation were collected in the altitude approximately 1,600 $\mathrm{m}$ above the sea level in the west slope of Mt. Yatsugatake, Nagano Prefecture, Japan in late August, 2009 (Fig. 2).

Growing young flower buds of the two species were collected from their flowering inflorescences. Their ovaries were cut into 1-2 mm pieces, and were immersed in $2 \mathrm{mM} 8$-hydroxyquinoline at $15^{\circ} \mathrm{C}$ for $4 \mathrm{~h}$. They were fixed in acetic alcohol $(1: 3)$ at $5^{\circ} \mathrm{C}$ for $24 \mathrm{~h}$. The fixed materials were hydrolyzed in a 1:2 mixture of $45 \%$ acetic acid and $1 \mathrm{~N} \mathrm{HCl}$ at $60^{\circ} \mathrm{C}$ for $30 \mathrm{sec}$. Then, immature

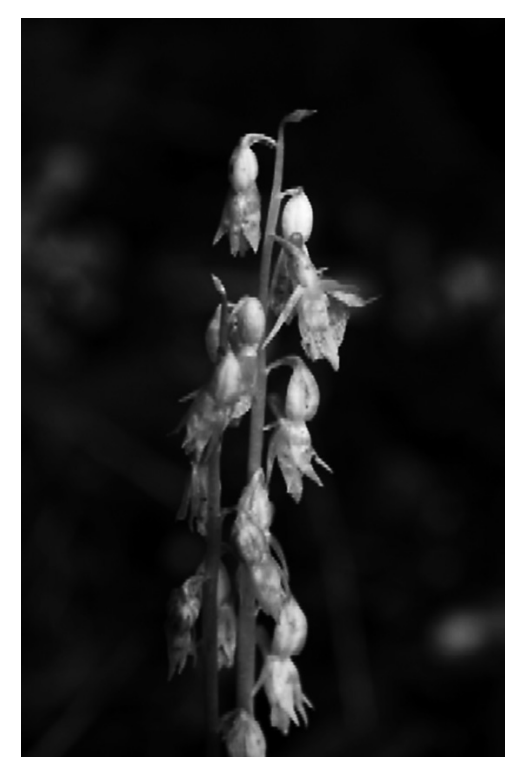

Fig. 1. Flowering Epipogium roseum in natural habitat in early July 2009. 


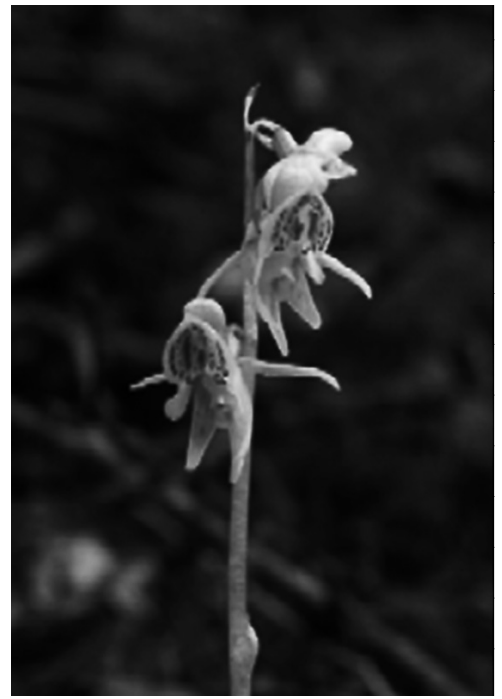

Fig. 2. Flowering Epipogium aphyllum in natural habitat in late August 2009.

placenta tissues with young ovules were separated from the inside of ovary on glass slides, and stained in $2 \%$ aceto-orcein by the usual squash method.

Classification for the chromosome types at resting and mitotic prophase stages followed Tanaka (1977). Terminology of chromosome morphology at mitotic metaphase on the basis of the position of the centromere followed Levan et al. (1964).

\section{Results and Discussion}

Epipogium roseum (D. Don) Lindl., $2 n=c a .70,2 n=35_{I I}$ and $n=35$. The young ovule showed both somatic mitosis in the integument tissues and meiosis in the embryo mother cells (Fig. 3D). The chromosomes of the species studied at resting stage formed darkly stained chromatin blocks, which were about 15 in number per nucleus (Fig. $3 \mathrm{~A})$. Thus, the chromosome features at resting stage were of the complex chromocenter type. The chromosomes at mitotic prophase formed early condensed segments located commonly in the proximal region (Fig. 3B).

The chromosome number of $2 \mathrm{n}=\mathrm{ca} .70$ were uniformly counted in three cells of the integument tissues at mitotic metaphase (Fig. 3C). Thirty-five bivalent chromosomes were counted in each of four embryo mother cells at meiotic metaphase I (Fig. 3E), and the haploid chromosome number of $n=35$ were counted in each of three embryo mother cells at meiotic metaphase II (Fig. 3F). The chromosomes in the complement at meiotic metaphase II varied gradually in length from $1.7-0.7 \mu \mathrm{m}$ (Fig. 3G). Among the 35 chromosomes, the largest one was submedian-centromeric, followed three (Nos. 2-4) were subterminal-centromeric, and the other 31 were unidentified their positions of centromeres. Thus, this species showed a homogeneous and gradual karyotype in length.

The chromosome number of $2 \mathrm{n}=\mathrm{ca} .70,2 \mathrm{n}=35_{\text {II }}$ and $\mathrm{n}=35$ found here for Epipogium roseum were different from the previous report of $2 n=68$ (Singh 1983).

Epipogium aphyllum $S w$., $2 n=72,2 n=36_{I I}$ and $n=36$. The chromosomes of the species studied at resting stage formed darkly stained chromatin blocks, which were about ten in number per nucleus (Fig. 4A). Thus, the chromosome features at resting stage were of the complex chromocenter type. The chromosomes at mitotic prophase formed early condensed segments located in the proximal and interstitial regions (Fig. 4B).

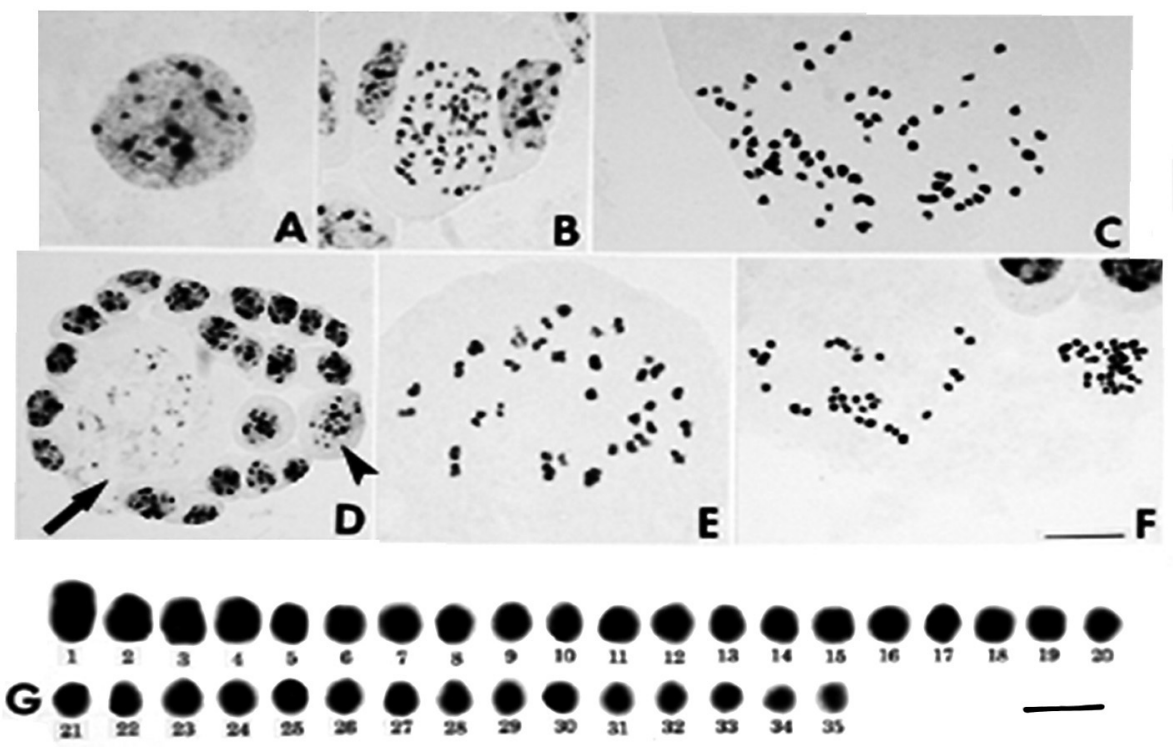

Fig. 3. Orcein-stained chromosomes of Epipogium roseum. A. Resting stage. B. Mitotic prophase. C. Mitotic metaphase, $2 \mathrm{n}=\mathrm{ca} .70$. D. The young ovule showed somatic mitosis (allow head) in the integument tissue and meiosis (allow) in the embryo mother cell. E. Meiotic metaphase I, 2n=35II. F. Meiotic metaphase II, n=35. $\mathrm{G}$. Chromosome alignment at meiotic metaphase II in decreasing order in length. Bar $=10 \mu \mathrm{m}$ in $\mathrm{F}$ for $\mathrm{A}-\mathrm{C}, \mathrm{E}$ and $\mathrm{F}$. Bar $=25 \mu \mathrm{m}$ in D. Bar $=2 \mu \mathrm{m}$ in $\mathrm{G}$. 


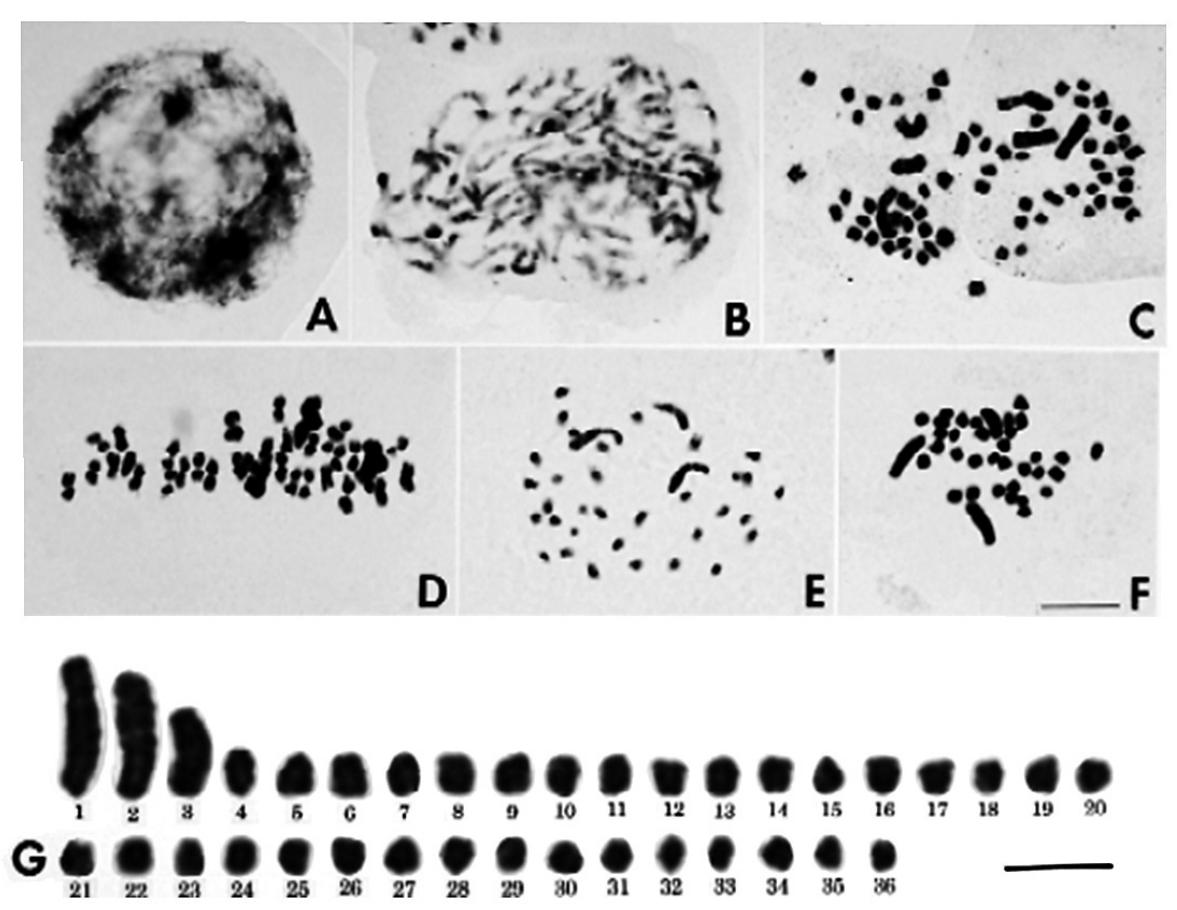

Fig. 4. Orcein-stained chromosomes of Epipogium aphyllum. A. Resting stage. B. Mitotic prophase. C. Mitotic metaphase, $2 n=72$. D. Meiotic metaphase I, $2 n=36$ II. E. Meiotic prometaphase II. F. Meiotic metaphase II, $n=36$. G. Chromosome alignment at meiotic metaphase II in decreasing order in length. Bar $=10 \mu \mathrm{m}$ in $\mathrm{F}$ for A-F. $\mathrm{Bar}=5 \mu \mathrm{m}$ in $\mathrm{G}$.

Table 1. Comparison of chromosome characrers in three species of Epipogium.

\begin{tabular}{llllcc}
\hline \hline species & $\begin{array}{l}\text { Karyotype } \\
\text { at resting stage }\end{array}$ & $\begin{array}{l}\text { Karyotype } \\
\text { at metaphase }\end{array}$ & $\begin{array}{l}\text { Chromosome } \\
\text { number }\end{array}$ & $\begin{array}{l}\text { Chromosome length } \\
\text { largest-smallest }(\mu \mathrm{m})\end{array}$ & $\begin{array}{l}\text { Total } \\
\text { length }(\mu \mathrm{m})\end{array}$ \\
\hline E. aphyllum & $\begin{array}{l}\text { complex } \\
\text { chromocenter }\end{array}$ & bimodal & $\begin{array}{l}2 \mathrm{n}=72,36_{\text {II }} \\
\mathrm{n}=36\end{array}$ & $6.5-1.4$ & 140 \\
E. roseum & $\begin{array}{l}\text { complex } \\
\text { chromocenter }\end{array}$ & gradual & $\begin{array}{l}2 \mathrm{n}=\mathrm{ca} .70,35_{\text {II }} \\
\mathrm{n}=35\end{array}$ & $1.7-0.7$ & 66 \\
E. japonicum* & diffused type & gradual & $2 \mathrm{n}=78$ & $2.0-1.2$ & 119 \\
\hline
\end{tabular}

* reffered from Aoyama (2008)

The chromosome number of $2 n=72$ were uniformly counted in two cells of the integument tissues at mitotic metaphase (Fig. 4C). The 36 bivalent chromosomes were counted in one embryo mother cell at meiotic metaphase I (Fig. 4D), and the haploid chromosome number of $\mathrm{n}=36$ were counted in nine embryo mother cells at meiotic prometaphase II (Fig. 4E) and meiotic metaphase II (Fig. 4F). The chromosomes in the complement at meiotic metaphase II showed a bimodal karyotype in length consisted with three large chromosomes varied from $6.5-4.2 \mu \mathrm{m}$ and 33 small chromosomes varied from 2.1-1.4 $\mu \mathrm{m}$ (Fig. 4G). Among the 36 chromosomes, the largest chromosome was submedian-centromeric, followed two large chromosomes (Nos. 2-3) were subterminal-centromeric, and one small chromosome was submedian-centromeric, ten small ones were subterminalcentromeric, rest 19 were unidentified their positions of centromeres. Thus, this species showed a heterogeneous and bimodal karyotype in length.

The chromosome numbers of $2 n=72,2 n=36_{\text {II }}$ and $n=36$ found here for Epipogium aphyllum were different from those of $2 \mathrm{n}=68$ (Gurzenkov 1973, Uhrikova and Majovsky 1980) and $n=34$ (Francini 1930, Afzelius 1954).

Comparison of chromosome characters in Epipogium Chromosome characters of E. aphyllum and E. roseum studied here were summarized in Table 1 with those of E. japonicum previously reported (Aoyama 2008). These three species were common in relatively large chromosome numbers in the members of Orchidaceae. While, they were differed each other in karyotypes at resting stage and metaphase chromosome, chromosome numbers, largest and smallest chromosome lengths and total chromosome lengths. The large chromosomes of E. aphyllum were heterogeneous in length in the chromosome complement of the genus. If it was thought that the one large chromosome of E. aphyllum was derived by the fusion of two small chromosomes, the chromosome number was converted to be $2 n=78$, of which was equal to that of E. japonicum. Furthermore, total chromosome lengths of 
$140 \mu \mathrm{m}$ in E. aphyllum and $119 \mu \mathrm{m}$ in E. japonicum were distinctly longer than $66 \mu \mathrm{m}$ in $E$. roseum. Thus, two species of E. aphyllum and E. japonicum were closely related than $E$. roseum karyomorphologically.

ACKNOWLEDGEMENTS. The author sincerely thanks to Dr Katsuhiko Kondo (Emeritus Professor of Hiroshima University; Professor of Tokyo University of Agriculture) for his critical reading of manuscript, and to Dr. Taro Seki (Emeritus Professor of Hiroshima University), Dr. Takahiro Yagame (Tottori University) and Dr. Tetsuya Sera (Hiroshima Botanical Garden) for suggesting and sampling the materials.

\section{Literature Cited}

Afzelius, K. 1954. Embryo-sac development in Epipogium aphyllum. Sv. Bot. Tidskr. 48: 513-520.

Aoyama, M. 2008. Cytological studies on two saprophytic orchid-species of Neottia asiatica Ohwi and Epipogium japonicum Makino. Chrom. Bot. 3: 49-52.

Francini, E. 1930. Primi dati di una revisione critica della sviluppo del gametofito gemmineo del genere Cypripedium. Nuovo Giornale Bot. Ital. 37: 277-278.

Govaerts, R., Pfahl, J., Campacci, M. A., Baptista, D. H., Tigges, H., Shaw, J., Cribb, P., George, A., Kreuz, K. and Wood, J. 2006. World Checklist of Orchidaceae. The Board of Trustees of the Royal Botanic Gardens, Kew. Published on the Internet; http://www.kew.org/wcsp/

Gurzenkov, N. N. 1973. Studies of chromosome numbers of plants from the south of the Soviet Far East. Komarov Lectures 20: 47-61.

Levan, A., Fredga, K. and Sandberg, A. A. 1964. Nomenclature for centromeric position on chromosomes. Hereditas 52: 201-220.

Singh, F. 1983. In IOPB chromosome number reports LXXVIII. Taxon 32: 140-141.

Tanaka, R. 1977. Recent karyotype study. pp. 293-326. In Ogawa, K., Kurozumi, K., Koike, S. and Sato, S. Eds., Plant cytology. Asakura Book, Tokyo, in Japanese.

Uhrikova, A. and Majovsky, J. 1980. In IOPB chromosome number reports LXIX. Taxon 29: 725-726. 